\title{
Awareness and Abuse of Ototoxic Drugs Among Health Professionals in Federal Teaching Hospital, Ido-Ekiti
}

\author{
Tobih J. E., Esan D.O., Esan T.O., Ossai I., and Adedeji T.O.
}

\begin{abstract}
Background of study-The challenge of hearing loss is global but worse in Africa. It heavily weighs adversely on the national economy, occupational productivity and social integration on the Individual and family affected and on the community and society at large. Injury to the ear which may lead to hearing loss have been attributed to many factors, one of the major factors, being drugs that are injurious to the ear commonly called ototoxic drugs. Other damaging factors are infections, noise, genetics and metabolic systemic diseases. The menace of ototoxic drugs is devastating in Africa because there is no legislation yet against these drugs hence they are still easily purchased without medical prescription. There are over 200 known ototoxic medications (both prescribe drugs and overthe-counter) in the market today. This study was therefore aimed at assessing awareness and abuse of ototoxic drug among health care professionals in a federal teaching hospital in Nigeria as a preliminary study to comprehensive solution to the challenges of hearing loss in Nigeria.

Methodology-A descriptive cross-sectional quantitative study with purposive sampling technique was used as the research design which is aimed at determining the awareness and abuse of ototoxic drugs among health professionals in a Federal Teaching Hospital A sample size of 365 participants was calculated for the research study but only 191 persons participated in the study comprising of 111 nurses, 47 doctors, 33 pharmacists. Semi- structured questionnaires were administered to the target group; Test-retest method was used to test the reliability of the questionnaire. Data was analyzed using SPSS and analysis was done at both univariate and bivariate levels.

Result-The findings from the study revealed that there was a high level of awareness of ototoxic drugs among health professionals $(94.8 \%)$ but prevalence $(66.5 \%)$ level of ototoxic drug was also high. Majority of the respondent have high level of awareness about ototoxic drugs, therefore use some of the drugs with precaution but it was found however that the prevalence of ototoxic drug was still high and this is found to be attributed to other compelling factors such as reduced price, readily available and shorter medication regime. Findings from the study also revealed that there is a significant relationship between level of education of respondents and their awareness about ototoxic drugs but there is no significant relationship between the profession of respondents and their awareness of ototoxic drug use.
\end{abstract}

Index Terms-Awareness, Abuse, Ototoxic drugs, Health Professionals, Hearing loss.

Published on December 23, 2019

J. E Tobih, and T. O. Adedeji (Corresponding Author) are with the Department of Ear Nose \&Throat/Head \&Neck Surgery, Ladoke Akintola University of Technology Teaching Hospital, Osogbo, Nigeria. (e-mail: doctadedejitaiwo@gmail.com)

D. O. Esan is with the Department of Nursing, Afe Babalola University Ado-Ekiti, Nigeria.

T. O. Esan and L. Ossai are with the Department of Ear, Nose \& Throat Federal Teaching Hospital, Ido-Ekiti, Nigeria.

\section{INTRODUCTION}

Hearing loss is one of the most common disorders in the world today. Loss can be congenital or acquired later in life [1]. Over 5\% of the world's population (360 million people) has disabling hearing loss (328 million adults and 32 million children). Disabling hearing loss refers to hearing loss greater than 40 decibels $(\mathrm{dB})$ in the better hearing ear in adults and a hearing loss greater than $30 \mathrm{~dB}$ in the better hearing ear in children. The majority of people with disabling hearing loss live in low- and middle-income countries particularly sub-Saharan Africa [2].

The challenge of hearing loss due to ototoxicity is significant, as epidemiological data has revealed that between 0.5 to $5 \%$ of every 1000 infants born will develop childhood disabling hearing loss due to the abuse of ototoxic drugs in pregnancy [3], [4].

Studies further revealed that the estimated incidence of early onset of hearing impairment and permanent congenital hearing loss is three times higher in the developing countries compared to the developed world [5], [6]. This may be due to reduced level of awareness and abuse of ototoxic drugs among the populace including even the health professionals

The incidence of Ototoxicity became noticed in the clinical sphere with the discovery of streptomycin in 1944 [6]. According to the World Health Organization a higher number of hearing impaired people resides in developing countries and while a number of etiological factors have been implicated as a cause of the impairment in these countries, ototoxicity from both antibiotics and antimalarial drugs feature prominently while aminoglycoside antibiotics ranks the commonest cause of ototoxicity [7]-[9]. Unethical prescription of aminoglycosides has been reported in many developing countries [10] and this unrestrained practice may keep eliciting a huge burden of hearing impairment unless a significant policy change comes into effect in these countries. Unfortunately, there is inadequate locally derived data coupled with weak political will to drive such a policy change.

Hearing ability is one of the key human senses and it could be argued to be essential for satisfactory quality of life. Loss of hearing in whatever degree therefore, may be a major disability [11]. This disability becomes more apparent in most developing countries where communal cultural setting is prevalent hence the hearing impaired people suffer from social stigmatization and isolation [12]. Hearing loss imposes significant social and economic disadvantages on both individuals, families and communities. [11]- [13]. Children with hearing impairment often experience delayed development of speech, language, and cognitive skills, causing slowed learning and difficult progress in school. 
Among adults, impairment of hearing makes it difficult to readily get a satisfactory job and keep it [13]. Hearing loss occurs via multiple pathways; hereditary, maternal illness in pregnancy, exposure to radiation, perinatal injuries such as birth asphyxia and kernicterus but inflammatory disease of the middle ear is one of the commonest cause in children, however, ototoxicity is an increasing cause of hearing loss in developing countries [2], [5], [14], [15].

otoxicity is drug or substance adverse reaction affecting the entire inner ear or isolated. Cochlear(auditory)or vestibular nerves, characterized by cochlear or vestibular dysfunction such as hearing loss, tinnitus, or balance disorders which may be temporary(reversible) or become permanent(irreversible). All drugs that has these tendencies are referred to as ototoxic. There are over 200 known ototoxic medications (both prescribe drugs and over-thecounter) in the market today. The most abuse and prevalent ototoxic drugs among health care professionals is Quinine (antimalarial) which has been found to be one of the commonest ototoxic drug in our environment [14].

\section{Data ANAlysis AND Results}

This research entails the use of self-administered paper and pencil questionnaire that was made as simple and clear as possible, with the target section and questions. Health care professionals were asked to participate in this study. Questionnaires were distributed to participants and an informed consent was obtained from them.

The data collected was analyzed with SPSS Version 20. Results was presented in tables, figures, frequency, charts and percentage. Inferential statistics (Chi-square) was used to test hypothesis.

One hundred and ninety one questionnaires were administered to health professionals (nurses, medical doctors and pharmacists) in the Federal Teaching Hospital, to assess their levels of awareness and abuse of ototoxic drugs. All the questionnaires were completely filled, returned, subjected to descriptive analysis and results presented as below

TABLE I: SOCIO-DEMOGRAPHIC CHARACTERISTICS OF RESPONDENTS

\begin{tabular}{lll}
\hline \hline Variable & $\begin{array}{l}\text { Frequency } \\
\mathbf{N}=\mathbf{1 9 1}\end{array}$ & $\begin{array}{l}\text { Percentage } \\
(\mathbf{\%})\end{array}$ \\
\hline Age group (in years) & 56 & 29.3 \\
$20-29$ & 79 & 41.4 \\
$30-39$ & 48 & 25.1 \\
$40-49$ & 8 & 4.2 \\
$50-59$ & $34.9 \pm 7.9$ & \\
Mean age $\pm S D$ & & \\
\hline Religion & 137 & 71.7 \\
Christianity & 48 & 25.1 \\
Islam & 6 & 3.1 \\
Others & & \\
\hline Marital Status & 45 & 23.6 \\
Single & 135 & 70.6 \\
Married & 11 & 5.8 \\
Divorced & & \\
\hline Ethnicity & 123 & 64.4 \\
Yoruba & 29 & 15.2 \\
Hausa & 39 & 20.4 \\
Igbo & & \\
\hline Education & 27 & 14.1 \\
Diploma & 77 & 40.3 \\
First degree & 87 & \\
Postgraduate degree & & \\
\hline \hline
\end{tabular}

TABLE II: LEVEL OF AWARENESS OF RESPONDENTS ABOUT OTOTOXIC DRUGS \& POSSIBLE SIDE EFFECTS OF OTOTOXIC DRUGS

\begin{tabular}{lll}
\hline Awareness about ototoxic drugs & $\begin{array}{l}\text { Frequency } \\
\text { N= 191 }\end{array}$ & $\begin{array}{l}\text { Percentage } \\
(\%)\end{array}$ \\
\hline Ever heard of Ototoxic drugs & 180 & 94.8 \\
Yes & 10 & 5.2 \\
No & $\begin{array}{l}\text { Frequency } \\
(\mathbf{n}=\mathbf{1 8 0})\end{array}$ & $\begin{array}{l}\text { Percentage } \\
\mathbf{( \% )}\end{array}$ \\
\hline Drugs you think can cause ototoxicity & 170 & 89.0 \\
\hline NSAID such as aspirin & 95 & 49.7 \\
Antimalaria such as chloroquine & 172 & 90.1 \\
Amynoglycoside such as gentamycin & 147 & 77.0 \\
Sulphonamide & 114 & 59.7 \\
Fluroquinolones such as quinine & 57 & 29.8 \\
Antiemetics such as metoclopramide & Frequency & Percentage \\
\hline Possible side effects of ototoxic drugs & $\mathbf{N = 1 9 1}$ & $\mathbf{( \% )}$ \\
\hline Tinnitus & 173 & 90.6 \\
Vertigo & 172 & 90.1 \\
Nausea & 106 & 55.5 \\
Hearing loss & 163 & 85.3 \\
Ear pain & 158 & 82.7 \\
Restlessness & 117 & 61.3 \\
\hline \hline
\end{tabular}

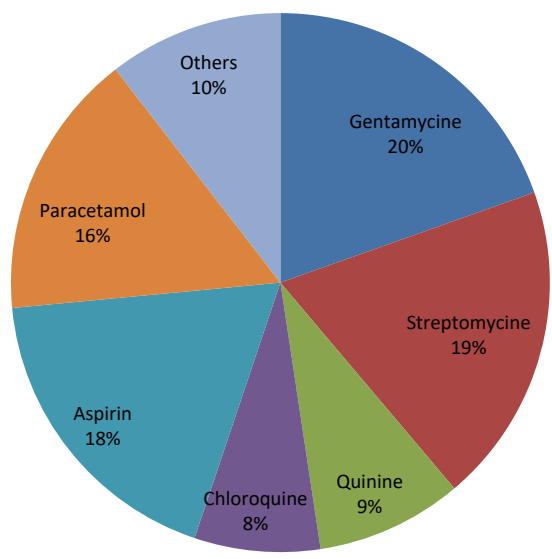

Fig. 1. Prevalence of ototoxic drug use/prescription among health professionals

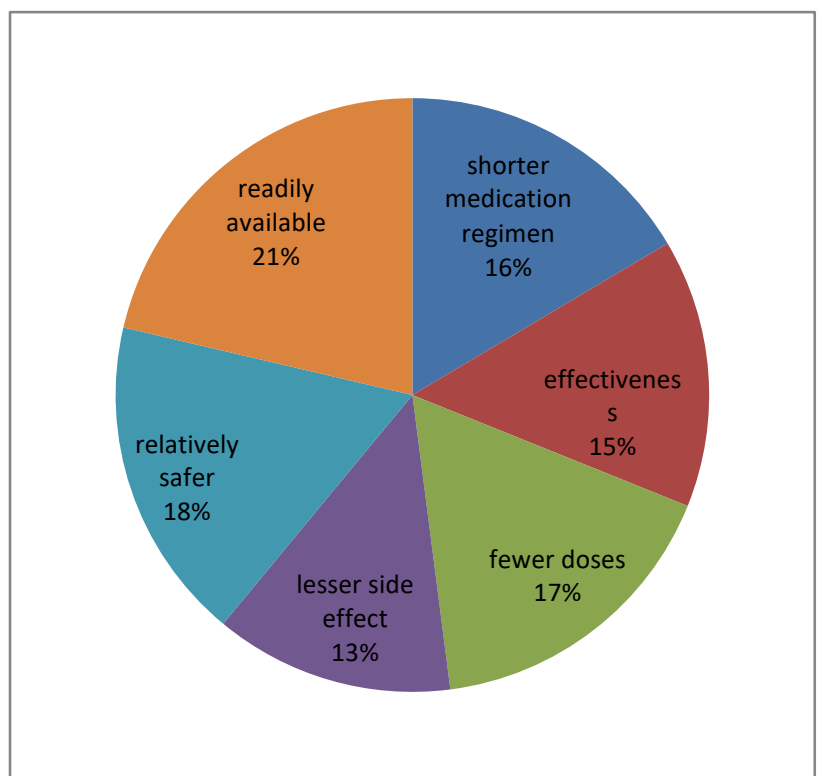

Fig. 2. Contributing factors toward abuse of ototoxic drugs among health professionals 
TABLE III: RELATIONSHIP BETWEEN PROFESSION AND AWARENESS OF OTOTOXIC DRUGS

\begin{tabular}{|c|c|c|c|c|c|}
\hline & & & \multicolumn{3}{|c|}{$\begin{array}{l}\text { Have you heard about } \\
\text { ototoxic drugs before Tot }\end{array}$} \\
\hline & & & Yes & No & \\
\hline \multirow{6}{*}{ Profession } & \multirow[b]{2}{*}{ Nurse } & Count & 98 & 9 & 107 \\
\hline & & $\begin{array}{l}\% \text { within } \\
\text { Profession }\end{array}$ & $91.6 \%$ & $8.4 \%$ & $100.0 \%$ \\
\hline & \multirow[b]{2}{*}{$\begin{array}{l}\text { Medical } \\
\text { Doctor }\end{array}$} & Count & 69 & 1 & 70 \\
\hline & & $\begin{array}{l}\% \text { within } \\
\text { Profession }\end{array}$ & $98.6 \%$ & $1.4 \%$ & $100.0 \%$ \\
\hline & \multirow[b]{2}{*}{ Pharmacist } & Count & 14 & 0 & 14 \\
\hline & & $\begin{array}{l}\text { \% within } \\
\text { Profession }\end{array}$ & $100.0 \%$ & $0.0 \%$ & $100.0 \%$ \\
\hline \multirow[b]{2}{*}{ Total } & & Count & 181 & 10 & 191 \\
\hline & & $\begin{array}{l}\% \text { within } \\
\text { Profession }\end{array}$ & $94.8 \%$ & $5.2 \%$ & $100.0 \%$ \\
\hline
\end{tabular}

TABLE IV: RELATIONSHIP BETWEEN EDUCATION AND AWARENESS OF OTOTOXIC DRUGS

\begin{tabular}{|c|c|c|c|c|c|}
\hline & & & \multicolumn{3}{|c|}{$\begin{array}{ll}\text { Have you heard } \\
\text { about ototoxic } & \text { drugs } \\
\text { before } & \end{array}$} \\
\hline & & & Yes & No & \\
\hline \multirow{6}{*}{$\begin{array}{l}\text { Educational } \\
\text { qualification }\end{array}$} & \multirow[b]{2}{*}{ Diploma } & Count & 20 & 7 & 27 \\
\hline & & $\begin{array}{l}\text { \% within } \\
\text { Educational } \\
\text { qualification }\end{array}$ & $74.1 \%$ & $25.9 \%$ & $100.0 \%$ \\
\hline & \multirow[b]{2}{*}{$\begin{array}{l}\text { First } \\
\text { degree }\end{array}$} & Count & 75 & 2 & 77 \\
\hline & & $\begin{array}{l}\% \text { within } \\
\text { Educational } \\
\text { qualification }\end{array}$ & $97.4 \%$ & $2.6 \%$ & $100.0 \%$ \\
\hline & \multirow[b]{2}{*}{$\begin{array}{l}\text { post } \\
\text { graduate }\end{array}$} & Count & 86 & 1 & 87 \\
\hline & & $\begin{array}{l}\text { \% within } \\
\text { Educational } \\
\text { qualification }\end{array}$ & $98.9 \%$ & $1.1 \%$ & $100.0 \%$ \\
\hline \multirow[b]{2}{*}{ Total } & & Count & 181 & 10 & 191 \\
\hline & & $\begin{array}{l}\% \text { within } \\
\text { Educational } \\
\text { qualification }\end{array}$ & $94.8 \%$ & $5.2 \%$ & $100.0 \%$ \\
\hline
\end{tabular}

\section{DISCUSSION OF FINDINGS}

Ototoxicity is injury to the cochlear and vestibular system of the inner ear caused by toxins. This results to damage to hearing and balance as a result of toxins in form of drugs and chemicals.

Hearing loss due to ototoxicity is said to account for $3 \%$ $4 \%$ of all deafness in children in developing countries [2] Ototoxicity affects all age groups, the young people appear to be more affected [7].

The damages to the auditory and vestibular systems usually manifest as hearing loss, tinnitus and vertigo. It is one of the diseases of public health importance in developing countries and the most common cause of avoidable deafness [16].

Most times it initially affects the higher frequencies but can progress to the speech frequencies with continued exposure [17].

There are diverse classes of drugs that have been implicated. Quinine was amongst the first drugs known to be associated with tinnitus, hearing loss and vertigo; others include aminoglycosides and other antibiotics, calcium channel blockers, chemotherapeutics with platinum base, salicylates and loop diuretics [18], [19]. Some of these drugs are either cochlotoxic or vestibulotoxic, however it can sometime be both. Aminoglycosides, streptomycin, gentamycin and tobramycin are known to be initially vestibulotoxic, however in further dose they can also be cochlotoxic. Type 1 cell of Crista ampullaris are affected in vestibulotoxicity. Neomycin, kanamycin, amikacin, sisomycin, and diydrostreptomycin are usually cochlotoxic; and the outer hair cells of the inner ear are usually affected.

Among notable ant-cancer drugs that has been found very potent and effective for testicular, ovarian, oesophageal and some Head and Neck cancers is cisplatin. Others are carboplatin and nitrogen mustard (mechlorethamine). They have all been found to have high potential for ototoxicity. Various studies have confirmed very high association of cisplatin with ototoxity. Several patients that have undergone chemotherapy with cisplatinin did complain and found to have some form of hearing loss and unfortunately its effect is irreversible [20], [21].

The damage caused by ototoxicity can either be temporary or permanent. Aminoglycosides and chemotherapeutic agent cause more of permanent damage while others such as quinine and aspirin cause temporary damage, hence damage can be reversed with discontinuation [22], [23].

Streptomycin, Amikacin, and Kanamycin are examples of aminoglycosides in the drug regime against tuberculosis. The study of streptomycin induced ototoxicity in patients with tuberculosis provides an excellent opportunity to monitor aminoglycoside ototoxicity within a developing country population [2].

The comprehensive survey of the pharmacological origin of sreptomycin with its ability to induce either harmful ototoxic effects or just a symptomatology like tinnitus or balance disturbances, without any cochlear or vestibular loss has widened in the last few years [25].

In this study, majority of respondents were between the ages of 30 and 39 years (41.4\%). Their mean age was 34.9 years \pm 7.9 with majority of them Christians $(71.7 \%)$, married $(70.6 \%)$, Yoruba $(64.4 \%)$ and with a postgraduate degree $(45.5 \%)$. There was a high level of awareness of ototoxic drugs (94.8\%). Reasons for this high awareness are not far-fetched as respondents are healthcare professionals (nurses, doctors and pharmacists). Despite this high level of awareness there is still a high level of prevalence of use and abuse of ototoxic drugs among health professionals in this centre as a result of other compelling factors which may be a reflection of what obtains in other centers. It is also noted that media contributed very little to the awareness and this organ supposed to be the main dissemination of this important information especially in Africa where majority don't have access to reading books. This is in contrast to the research carried out by Duthey where there is abysmal ignorance on the part of both health care professionals and the general population concerning many prescription drugs that can indeed damage the ears. He observed that the word ototoxicity is a strange one to the population and the damage these drugs may cause is never in their consciousness at all Unfortunately, the damage to the ear does not always show up immediately when taking the prescribed drug until weeks or even months later. By then it's too late for the doctor to do much about it. This calls for intensive heath education to every segment of the populace. [26].

About $73.3 \%$ of the health workers used or prescribed ototoxic drugs only as needs arose. While $14.7 \%$ of them were using or prescribing these drugs frequently, $12.0 \%$ 
were doing same occasionally. It is also shown in this study that health professional was most prevalently using or prescribing gentamycin (66.5\%), streptomycin (65.4\%), aspirin $(62.3 \%)$ and paracetamol $(54.5 \%)$. In order words all the professionals do prescribe these drugs for one reason or the other. There is none that has concluded on alternative to these drugs. This will still pass as high level of use and abuse which is very comparable to finding of a previous work conducted among TB patients [12].

Another susceptible group to ototoxicity are the pregnant women who are on various drugs. Again due to all the factors mentioned above such as lack of awareness and high prevalence in the developing populace coupled with ready availability of these toxic drugs It has been shown that use of non- prescribed drugs or abuse of prescription drugs by pregnant women and nursing mothers can have severe hearing consequences for infants. This is because many substances pass easily through the placenta, so substances that a pregnant woman takes also, gets to the baby [24], [25]

One study of hard of hearing children in China revealed that 123 of the 154 children studied had lost their hearing from taking antibiotics. Of these 123 children, 60 of them had hearing problems due to the Aminoglycoside Antibiotics and Gentamicin which mothers took during pregnancy and which were also administered to their children [25]- [28].

\section{CONCLUSION}

The study has shown that there is a high level of awareness of ototoxic drug among health care professionals though prevalence level is still high. It is found that other factors that are compelling in the high prevalence and abuse of these drugs are they are relatively cheaper than others, readily available and shorter duration of intake We also found that the media which supposed to be the main organ of this public heath enlightenment is not doing much to increase the awareness not just among Health Professionals but the entire populace. It is alarming that if the level of prevalence and abuse of ototoxic drugs is high among the Health professionals of high cadre it is left to imagination what obtains among the general populace. This calls for urgent aggressive public health campaign and government strategic policy intervention that will also address the issue of adequate provision of alternative drugs with concurrent friendly costs.

\section{REFERENCES}

[1] American Academy of Pediatrics; Joint Committee on Infant Hearing. Year 2007 position statement: principles and guidelines for early hearing detection and intervention programs. Pediatrics 2007; 120: 898-921. PMID: 17908777

[2] (World Health Organization. Program me for the Prevention of Deafness and Hearing Impairment. Report of an Informal Consultation on Strategies for Prevention of Hearing Impairments from Ototoxic Drugs, WHO/PDH/95.2. Geneva: World Health Organization; 1995. Available from: http://www.who.int/iris/handle/10665/62065)2.2.

[3] Jamison, DT, Breman, JG, Measham, AR. Disease Control Priorities in Developing Countries. 2nd ed. New York, NY: Oxford University Press; 2006. Google Scholar

[4] Olusanya, BO, Newton, VE. Global burden of childhood hearing impairment and disease control priorities for developing countries.
Lancet. 2007; 369:1314-1317. doi:10.1016/S0140-6736(07)60602-3. Google Scholar $\mid$ Crossref $\mid$ Medline

[5] Swanepoel, D, Störbeck, C, Friedland, P. Early hearing detection and intervention in South Africa. Int J Pediatr Otorhinolaryngol. 2009; 73:783-786. doi: 10.1016/j.ijporl.2009.01.007. Google Scholar | Crossref | Medline

[6] Holden-Pitt, L, Albertorio, J. Thirty years of the Annual Survey of Deaf and Hard-of-Hearing Children \& Youth: a glance over the decades. Am Ann Deaf. 1998; 143:72-76. doi:10.1353/aad.2012.0630. Google Scholar | Crossref | Medline | ISI

[7] Obasikene, G., Adobamen, P., Okundia, P., Ogusi, F.O. (2012). Prevalence of ototoxicity in University of Benin Teaching Hospital, Benin City a 5-year review. Nigeria Journal of clinical practice. 2(15): $15-20$

[8] Peloquin et al., (2004). Aminoglycoside Toxicity. Daily versus Thrice-Weekly Dosing for Treatment of Mycobacterial Diseases. 17(5): 3-6.

[9] Rybak, L. P., Kelly, T. (2013). Ototoxicity: Bioprotective mechanisms. Current Opinion in Otolaryngology \& Head \& Neck Surgery. 11(5): 328-33.

[10] Gwimile, j., Shekalaghe, S., Kapanda, G., Kisanga, R. (2012). Antibiotic prescribing practice in management of cough and/or diarrhoea in Moshi Municipality, Northern Tanzania: cross-sectional descriptive study. Retrieved Retrieved from http://www.panafricanmed-journal.com/content/article/12/103/full/

[11] Lieu, JE. Speech-language and educational consequences of unilateral hearing loss in children. Arch Otolaryngol Head Neck Surg. 2004; 130:524-530. doi:10.1001/archotol.130.5.524. Google Scholar Crossref | Medline

[12] Le Roux, T, Swanepoel de, W, Louw, A, Vinck, B, Tshifularo, M. Profound childhood hearing loss in a South Africa cohort: risk profile, diagnosis and age of intervention. Int $\mathrm{J}$ Pediatr Otorhinolaryngol. 2015; 79:8-14. doi: 10.1016/j.ijporl.2014.09.033. Google Scholar | Crossref | Medline

[13] Mohr, PE, Feldman, JJ, Dunbar, JL. The societal costs of severe to profound hearing loss in the United States. Int $\mathrm{J}$ Technol Assess Health Care. 2000; 16:1120-1135. Google Scholar | Crossref | Medline | ISI

[14] Allen, TE. Patterns of academic achievement among hearing impaired students: 1974 and 1983. In: Schildroth, AN, Karchmer, MA eds. Deaf Children in America. Boston, MA: College-Hill Press; 1986:161-206. Google Scholar

[15] Harris, A.S., Elhassan, H.A., \& Flook E.P. (2016). Why are ototopical aminoglycosides still first-line therapy for chronic suppurative otitis media? A systematic review and discussion of aminoglycosides versus quinolones. Journal of Laryngology Otolology, 1(2):22-33.

[16] Smith AW. The World Health Organisation and the prevention of deafness and hearing impairment caused by noise. Noise Health 1998; 1:6-12)

[17] Fausti SA, Henry JA, Schaffer HI, Olson DJ, Frey RH, McDonald WJ, et al. High-frequency audiometric monitoring for early detection of aminoglycoside ototoxicity. J Infect Dis 1992; 165:1026-32)

[18] Lasak, J. M., Allen, P., McVay, T., Lewis, D. (Mar 2014). "Hearing loss: diagnosis and management". Primary care. 41 (1): 19-31.

[19] Buszman E, Wrzenisck D, Matusinki B. Ototoxic drugs. Aminoglycoside antibiotics. Wiad Lek 2003; 56:254-9.

[20] Hayes DM, Cvitkovic E, Golbey RB, Scheiner E, Helson L, Krakoff $\mathrm{IH}$, et al. High dose cis-platinum diammine dichloride: Amelioration of renal toxicity by mannitol diuresis. Cancer 1977; 39:1372-81)

[21] Bokemeyer C, Berger CC, Hartmann JT, Kollmannsberger C, Schmoll HJ, Kuczyk MA, et al. Analysis of risk factors for cisplatininduced ototoxicity in patients with testicular cancer. Br J Cancer $1998 ; 77: 1355-62)$

[22] Jung TT, Rhee CK, Lee CS, Park YS, Choi DC. Ototoxicity of salicylate, nonsteroidal anti-inflammatory drugs, and quinine. Otolaryngol Clin North Am 1993; 26:791-810.

[23] Schaacht J,Talaska AE, Rybak LP, . Cisplatin and aminoglycoside antibiotics;Hearing loss and itsprevention. AnatRec9Hoboken) 2012,295:1837-50,

[24] Ravi, D, Hanumanth, P. M., Sahana, P., \& Lakshmi, M. S. (2017). A qualitative study on knowledge and attitude towards risk factors, early identification and intervention of infant hearing loss among puerperal mothers. A short survey. 13(3): 54-68.

[25] Nora, J. J., Nora, A. H., Sommeroille, R. T. (2014). Maternal exposure to potential teratogens. JAMA 202:1065-1069.

[26] Food and Drug Administration. (2014). FDA issues final rule on changes to pregnancy and lactation labeling information for prescription drug and biological products. Retrieved from 
www.fda.gov/NewsEvents/Newsroom/PressAnnouncements/ucm425 317.html

[27] Jayawickrama, H. S., Amir, L. H., Pirotta, M. V. (2010) GPs' decision-making when prescribing medicines for breastfeeding women. Content analysis of a survey. 3(4):10-24.

[28] Nice, F. J., Luo A. C. (2012). Medications and Breastfeeding. Journal of the American Pharmacists Association 52(1): 86-94. 